\title{
READING COMPREHENSION QUESTIONS DEVELOPED BY ENGLISH TEACHERS OF SENIOR HIGH SCHOOLS IN SURABAYA
}

\author{
Mukhlisatun Muayanah
}

\begin{abstract}
:
According to the Competence Based Curriculum (KBK) in the subject of English at Senior High School, the reading skill emphasizes the ability to read written English in the forms of narration, spoof/recount, procedures, report, news items ( $1^{\text {st }}$ grade), anecdote, exposition, hortatory exposition ( $2^{\text {nd }}$ grade), descriptions, explanation, discussion, and commentary ( $3^{\text {rd }}$ grade). Therefore, the objective of teaching reading is to enable the students to have the ability to comprehend and interpret the content of many types of written English discourse.
\end{abstract}

Keywords: Barrett's Classification System, Reading Comprehension Questions

Basically, reading at any level is taught to enable the learners to develop basic comprehension skills, so that they can read and understand texts of a general nature (Grant, 1991). Grellet (1991) defines the reading comprehension skills as abilities to extract the required information from written text as efficiently as possible. As it is written in Oxford Dictionary (1991:286), comprehension is the capacity for understanding fully; the act or action of grasping with the intellect. Reading is to understand the meaning of written or printed materials.

Barrett taxonomy (www.eltnews.com/features/thinkntank/021lmh. shtml) categorizes reading comprehension skills into five levels of comprehension. They are presented in the hierarchy from the lowest to the highest level of reading, they are literal, reorganization, inference, evaluation and appreciation.

Ideally, teachers are expected to be able to help students to read with understanding as stated in the standard of competence for reading comprehension. One of the ways is by developing reading comprehension questions. Questioning constitute such a vital part of teaching (and of communication in general). In other word, questions are very important in the development of concepts. Questions help students to progress from one cognitive level to another by means of a variety of carefully planned questions, pupils can be helped to draw upon existing knowledge and understanding in order to develops new ideas and formulate conclusion. 
Researches on the reading comprehension questions of the English course books for Junior or Senior High Schools have been conducted by some researchers. Sunggingwati (2001) analyzed comprehension questions types and levels of English course book for Junior High School students based on Barrett's taxonomy. She found out that the reading comprehension questions in the course books, which consist of three series, cover three levels of comprehension, namely literal, inference, and evaluation. Literal is the most dominant type of comprehension questions in these books. Inferential questions are dominant in book 1, less dominant in book 3 and book 2. Let's Learn English 1 has more questions in the level of evaluation than book 3 and 2. She concluded that the reading comprehension questions in the textbook have not fully represented all levels of comprehension especially the higher level of comprehension in Barrett's taxonomy. The other research was conducted by Tjahjaning Tingastuti (1991). She analyzed the effect of using different types of questions on students' reading ability. The findings show that reading comprehension questions on the level of comprehension, application, and analysis in Bloom's Taxonomy can promote students' reading ability.

Thus, this study is done for several reasons. First, the importance of having knowledge on the types and levels of reading comprehension questions. Knowledge on types and levels of reading comprehension questions can be used to guide and develop students' reading comprehension. Second, based on the researcher's experience in analyzing the teacher's reading comprehension questions, English teachers often use the available questions in the English course books instead of developing their own questions. Unfortunately, some research findings (Sunggingwati, 2001; Wulandari, 2003; Aryati, 2007) show that high percentage of questions in the English course books deal with literal comprehension - the lowest level of comprehension. The last but not the least, the fact that using different types and levels of comprehension questions can promote students' reading ability (Tjahjaning, 1991) suggests that it is important for the English teachers to have good competence in developing reading comprehension questions by using various type and level of comprehension. Therefore, it is necessary to investigate the reading comprehension questions developed by English teachers. 
Question that prompt recall of information, shape understanding, and encourage reflection play an important role in the learning process (Morgan and Saxon, 1994:41). Furthermore, they points out that "question-asking is the most important intellectual tool". Questions shape students' comprehension and concept of what is important in a text: what a teacher asks is what students learn. The kinds of questions determine the kind of thought process necessary to answer it (Cook, 1970:5). Questions are a vehicle for developing thinking skills and can be used to develop concepts, build background knowledge, clarify reasoning, processes, and even lead students to higher levels of thinking (Gunning, 2000:260). By asking the right questions, teachers can lead students into all kinds of thinking and help them develop a variety of skills.

Questions function in both reading and teaching situations. In reading, they establish a basis for understanding and clarifying a reader's purposes; this influences the method of reading, degree of comprehension, reading rate, and the skills employed. Richard, Platt, and Platt (1992:303) define question as:

A sentence which is addressed to a listener/reader and askl for an expression of fact opinion, belief, etc. In English, questions may be formed: (a) by the use of a question word such as what, how, when, where, why; (b) by the use of an operator in the first position in a sentence, as in Can she come?; (c) through the use of intonation, as in She isn't married?; and (d) by the use of question tag such as isn't it; it is, can he, won't he, do you, etc; for example: Patricia is a students, isn't she?

Questions function in both reading and teaching situation. In reading, questions establish a basis for identifying and clarifying a reader's purpose; this influences the method of reading, degree of comprehension, reading rate, and the skills employed. In teaching situation, students' concepts of reading are largely influenced by the type of questions their teacher ask. Questions may cause wonder, uncertainty, doubt, or suspicion. Yet, used appropriately, they can lead to new knowledge and skill, help to quell controversy, and promote useful discussion. Richards, Plat, and Platt (1992:303) define that question is a sentence which is addressed to a reader and asks for an expression of fact, opinion, belief, etc, that can be formed by using a question word, by using an operator in the first position in a sentence as in Can you come?, using intonation, using a questions tag such as isn't she, can he, won't you, etc. 
This definition help the investigator focuses on types and levels of questions for this study. The question types were those formed by a question word (wh-questions) such as what, when, where, why, who, and how. And those that require a yes or no response.

\section{Type 1. Wh-questions}

Wh- questions are questions beginning with where, when, who, why, and how. They require readers to provide specific content information in their answers. Such questions require the student to compose any response that seems suitable for him. According to Day and Park (2005), Wh- questions are excellent in helping the student with a literal understanding of the text, and making inferences, evaluations, and appreciations. They are also use as follow-ups to other questions forms, such as yes/no and alternative questions.

\section{Type 2. Yes/No- Questions}

Yes/no questions are simply questions that can be answered with either yes or no. Those questions require readers to show their agreement or disagreement on an issue or statement. For example, Is the chapter 2 of this thesis about review of related literature? This is a common form of comprehension question, but it has drawback of allowing $50 \%$ chance of guessing the correct answer. So, when using yes/no questions, it is recommended to follow up with other form of questions to ensure that the student understood the text. For example, do you like reading? Why? The follow-up questions are more useful in helping the student than the initial yes/no questions since it encourage the student to struggle understanding the text.

\section{Type 3. "Other" Questions}

The questions that cannot be grouped as wh-questions and yes/no questions are grouped as "other". The questions require students/readers to retell the story, connect the story to a situation, describe an incident, or relate the story to their behavior.

The main purpose of Bloom's taxonomy was to classify educational objectives, but it was later also applied to the areas of instructional and 
evaluation. It is divided into three large areas or domains: (a) the cognitive domain, (b) the affective domain, and (c) the psychomotor domain. The cognitive domain refers to the intellectual activities involved in learning and is composed of a six-level hierarchy: knowledge, comprehension, application, analysis, synthesis, and evaluation. The first level, knowledge, involves the recalling of facts, events, and details. Comprehension, the second level, refers to one's ability to go beyond knowledge to translate and explain information. Application, the third level, refers to applying information to existing or hypothetical situations. Analysis involves critical investigation of information received. in a more creative format. The sixth level is evaluation, or one's ability to place value on the importance of an idea and judge it using established criteria (Swaby, 1984:95).

Table 1

Bloom's Classification System

\begin{tabular}{|c|l|}
\hline Level & \multicolumn{1}{|c|}{ Operation for Learning Outcomes } \\
\hline Knowledge & $\begin{array}{l}\text { Involves recall of information and knowing; } \\
\text { illustrated by telling, citing, showing, listing, } \\
\text { locating, stating, reciting, repeating. }\end{array}$ \\
\hline Comprehension & $\begin{array}{l}\text { Refers to understanding or apprehension of } \\
\text { material and ability to make use of it; illustrated } \\
\text { by describing, explaining, reviewing, inferring, } \\
\text { translating, paraphrasing, predicting, } \\
\text { summarizing, discussing. }\end{array}$ \\
\hline Application & $\begin{array}{l}\text { Ability to use abstractions in concrete situations } \\
\text { and apply them to other instances; illustrated by } \\
\text { modeling, trying, operating, manipulating, } \\
\text { diagramming, demonstrating. }\end{array}$ \\
\hline Analysis & $\begin{array}{l}\text { Process of breaking down communication so } \\
\text { that ideas are explicit; illustrated by organizing, } \\
\text { making connections, categorizing, scrutinizing, } \\
\text { dissecting, proving, inspecting. }\end{array}$ \\
\hline Synthesis & $\begin{array}{l}\text { Ability to put elements or parts together to make } \\
\text { a whole; illustrated by explaining, creating, } \\
\text { composing, hypothesizing, deducing, imagining, } \\
\text { formulating, elaborating, designing. }\end{array}$ \\
\hline Evaluation & $\begin{array}{l}\text { Judging the value of methods and materials for } \\
\text { set criteria; illustrated by justifying, apprasing, } \\
\text { recommending, criticizing, supporting, } \\
\text { reflecting, awarding, censuring. }\end{array}$ \\
\hline
\end{tabular}


This taxonomy is designed to capture relationship between information in the text and that which has to come from the reader's store of prior knowledge. It classifies relations that exist between questions and responses. Pearson and Johnson taxonomy (in Scales and Shen (2001), involves the tasks with nine level and a taxonomy of prepositional comprehension tasks also containing nine categories. Tabel 2 shows their question taxonomy, however, consists of only three levels: (a) textually explicit questions, (b) textually implicit questions, and (c) "scriptally" implicit questions.

Table 2

Pearson and Johnson's Classification System

\begin{tabular}{|c|l|}
\hline \multicolumn{1}{|c|}{ Levels } & Operations for Learning Outcomes \\
\hline Textually explicit & $\begin{array}{l}\text { Question and answer are cued by } \\
\text { text language; illustrated by reading } \\
\text { the lines }\end{array}$ \\
\hline Textually implicit & $\begin{array}{l}\text { Question and answer are not bound } \\
\text { by language cue on the page; } \\
\text { illustrated by reading between the } \\
\text { lines }\end{array}$ \\
\hline Scriptally implicit & $\begin{array}{l}\text { Text question with nontextual } \\
\text { response; illustrated by reading } \\
\text { beyond the lines }\end{array}$ \\
\hline
\end{tabular}

Barrett classification system was influenced by Bloom. The table 1 below, shows the four major categories in this taxonomy, namely literal recognition or recall, inference, evaluation, and appreciation.

Table 3

Barrett's Classification System, by Levels and Operations

\begin{tabular}{|l|l|}
\hline Level & Operation for Learning Outcomes \\
\hline $\begin{array}{l}\text { Literal recognition } \\
\text { or recall }\end{array}$ & $\begin{array}{l}\text { Requires locating or identifying explicit } \\
\text { information or situation; illustrated by recognizing } \\
\text { or recalling details and main ideas, sequencing, } \\
\text { comparing, examining cause/effect relationships } \\
\text { and character traits. }\end{array}$ \\
\hline Reorganization & $\begin{array}{l}\text { Requires classifying, outlining, synthesizing, } \\
\text { and/or organizing ideas. }\end{array}$ \\
\hline
\end{tabular}




\begin{tabular}{|l|l|}
\hline Inference & $\begin{array}{l}\text { Requires thinking and imagination beyond the } \\
\text { printed page; illustrated by inferring supporting } \\
\text { details and main idea, sequencing, comparing, } \\
\text { examining cause-effect relationships and character } \\
\text { traits, predicting outcomes, focusing on figurative } \\
\text { language. }\end{array}$ \\
\hline Evaluation & $\begin{array}{l}\text { Requires determining the truthfulness of text; } \\
\text { illustrated by judgment of reality or fantasy, fact } \\
\text { or opinion, adequacy or validity, appropriateness, } \\
\text { desirability or acceptability. }\end{array}$ \\
\hline Appreciation & $\begin{array}{l}\text { Involves increasing sensitivity to various types of } \\
\text { literary genres; illustrated by emotional response } \\
\text { to plot or theme, identification with characters and } \\
\text { incidents, reactions to the author's use of } \\
\text { language, response to generating images. }\end{array}$ \\
\hline
\end{tabular}

According to Nuttal (1989) comprehension questions should reflect the process of comprehending of the given text. Not all questions fulfill the requirement of comprehension questions. In this case, Nuttal best describes a checklist that can be used to assess questions. They are as follows.

1. Can the questions be answered without reading the text?

The answer should be no. Reading is the process of interaction between the reader, the writer, and the text. If the text can be comprehended without reading it, it is not a process of understanding a text. This question is also called as unsatisfactory question.

2. Are there several questions on every part of the text?

This is not a principle to be maintained at all costs, but it is unusual to find a part of text that is not worth any attention.

3. Are the questions varied enough?

To stimulate the learners' understanding of a text, the questions should involve various types of comprehension. Nuttal (1989) argues that to divide questions into several types is not particularly helpful, except for evaluating the questions found in teachers' text-based questions. Many questions cover literal comprehension, with a few types of appreciation. Literal comprehension is an essential preliminary to any work on the text. But inference and evaluation should be the most concern since the questions of these types force the readers to think about not just what the writer has written, but how he has written it. 
The types of comprehension questions can be asked from the most elementary level.

4. Do some questions specifically try to make students aware of the strategies a reader needs?

Broadly, the questions must help the reader to interact with the text. Some questions may result in scanning and skimming activities. Others may direct the readers' attention to diagrams or other non-text features that will help him interpret the text.

5. Do the questions attempt to help students to understand?

The variety of comprehension questions can be approached trhough various forms of questions. As Day and Park (2005) argue, certain type of question can be presented in particular form of questions. For example, alternative questions work best with literal, reorganization, inference, and prediction. However, they do not lend themselves as well to evaluation and appreciation.

6. Are they written in language that is more difficult than the text?

The questions asked should be written clearly using language that is not too difficult to understand.

7. Do the answers require language that is too difficult for the students to handle? The answers should be the result of the reader's interaction with the text. Thus, the answers should not require language that is too difficult to write. Considering the guidelines, the researcher used the first criteria to examine the questions and to answer the third research question as it is focused more on the reading comprehension.

\section{Methodology Research Design}

Based on the characteristics of data, this study is a descriptive study. It uses qualitative approach. Hence, this research fulfils some characteristics of qualitative approach. First, This approach uses words, sentences, and discourse, as data that are going to be analyzed to make general conclusion of the subject of study. The data of this study were the questions made by English teachers of Senior High Schools in Surabaya. Furthermore, Bogdan (1998: 4-7) proposed five characteristics of 
qualitative research. The first feature is that qualitative research is naturalistic. It has actual settings as the direct source of data and the researcher is the key instrument. The data was collected through providing five reading texts. Then asked teachers to make reading comprehension questions and also the answers based on the text given. The data obtained by the researcher would interpreted and analyzed carefully in order to answer the predetermined research questions. The reading comprehension questions would be categorized into types of questions. Then, they would be classified into the levels of comprehension. The researcher is the primary instrument in data collection in which the researcher, in this study, selected texts appropriate to Senior High School students, asked teachers to make several comprehension questions related to the texts, and analyzed the data. Third, the data tend to be analyzed inductively. Qualitative researchers do not search out data or evidence to prove or disprove hypotheses. Next, the use of criteria for judging a qualitative study that differs from quantitative research.

\section{Sample}

The subjects were the English teachers of Senior High Schools in Surabaya who join the Musyawarah Guru Mata Pelajaran (MGMP) of Surabaya. They were chosen because of several reasons. The choice of MGMP was based on the fact that it has members of teachers from different schools in Surabaya. The members were all of English teachers of Senior High School in Surabaya. They meet once a month to discuss several topics in teaching and learning of English. The teachers in MGMP come from various schools, state and private Senior High Schools in Surabaya with different status, favorite (accredited A) and non-favorite schools. They had different experiences and age ranges. 20 of them were chosen as the subjects of this study. The decision was based on several reasons. Firstly, they are willingness in joining this study. The teachers were interviewed to know whether they wanted to be the subject of this study with the consequences. The second reason was they have sufficient time to do the tasks provided by the researcher. And the last is the principal or school authority give permission to the researcher to do this study. 


\section{Data Collection}

Data was taken from reading comprehension questions developed by teachers. The data were collected from August until the middle of September 2010. In order to get the data, the researcher used the following procedure.

Firstly, the researcher made an appointment with each participant in his or her school to discuss about the time and place where the task would be taken place. All of teachers agreed to do the test in their schools when they had no class to teach.

Secondly, to give clear description about what they had to work out the task, brief explanation about developing reading comprehension questions, types and levels of question were discussed. The teachers' task was to make reading comprehension questions in various question types and levels of comprehension. In other words, their questions would be grouped as Yes/No questions, Wh-questions, and "other". Yes/No questions require readers to show their agreement or disagreement on an issue or statement; Wh-questions require readers to provide specific content information in their answers; and "other" require readers to retell the story, connect the story to a situation, describe the incident, or relate the story to their behavior. The questions, then were classified into the level of comprehension based on Barrett's taxonomy including literal, reorganization, inferential, evaluation, and appreciation.

The last step was to provide three reading texts and asked the teacher to develop 10 questions for each text. The time allotment to do this task was about 45 to 60 minutes per text. Considering the teachers' request, each text was given in different time. The second text was given in the following week and so was the third one.

\section{Data Analysis Technique}

In order to answer the first research question about the type of reading comprehension questions developed by English teacher of SMA in Surabaya, the data were coded e.g. (A/1/1) means that the question was taken from teacher $\mathrm{A}$, text 1 and question number 1 . Then, all the data were categorized into types of questions. To answer the second research questions, the levels reading comprehension 
questions, the researcher used Barrett reading comprehension taxonomy for classification.

\section{Results Types of Reading Comprehension Questions}

Teachers ask reading comprehension questions in order to obtain information about the students' understanding of the text. Therefore, the situation and the information needed will influence the types of questions asked. There are three types of questions that are used to categorize questions in this study.

\section{Yes/No questions}

There are 32 questions that belong to Yes/No question type. As the name implies, the answer to a yes-no question is either 'yes' or 'no'. The samples of the questions are as follows.

- $\quad$ Have you ever visited such places described in the story? (B/1/6)

- Was the writer eager to go to the director's office? (C/1/1)

- Was the project successful? (G/2/6)

- Is MacQuarie University a tiny one? (C/3/1)

All of the questions above require the students to answer with either 'yes' or 'no'. Although, this is a common form of comprehension question, some problem might be faced. If students can answer the questions correctly, teachers might not know if they really understand the passage. If they get a question wrong, they might misunderstand the text or misunderstand the question. Since the questions come at the end, they might not know what they were supposed to find out. In this case, the follow-up questions are necessary. These questions are found in teachers' reading comprehension questions.

\section{Wh- questions}

There are $393(87,3 \%)$ Wh-question. The following are the samples of the questions.

- Where did the event take place? (A/1/1)

- Who was Young Il? (M/1/5)

- How does Bali Starling project conduct its project? (D/2/6)

- Why is MacQuarie University called the most attractive natural campus? $(A / 3 / 5)$ 
- When was the university firstly open? (F/3/9)

All questions in the examples above are categorized into wh- questions because where, who, how, why, and when are used at the beginning of the sentences. Wh- question is the most common type used by teachers in the three texts. 134 of 393 questions are wh- questions type of text 3,131 are in text 1, and the lowest portion (128 questions) are in text 2. it is also found that teacher A wrote 30 wh-questions. It means that he did not employ other questions instead of wh- questions.

\section{3. "Other" questions}

Besides using Yes/No and Wh-Questions, the teachers also used other types of questions. Those questions are called as "other" questions. The questions that are grouped as "other" questions are those that could not be grouped as either yesno or wh- questions. They might ask students to retell the story, describe an accident, name the characters in the text, find out a specific term in the text, or suggest recommendations to some problems in the text. In other words, the questions in this type use imperative sentences. The followings are some of questions found in the data.

- Mention the writer's difficulties in performing her tasks! (G/1/7)

- Name the characters described in the text? (I/1/2)

- The writer puts "however" in the fourth paragraph to describe ..... $(E / 2 / 5)$

- Describe the Mars Creek Zone clearly! (M/3/6)

\section{The levels of Reading Comprehension Questions.}

\section{Literal Comprehension}

Table 10 shows that there are 271 literal comprehension level. Among 271, 155 questions ask recognition or recall of details, 70 questions are recognition or recall of main idea and 13 questions are recognition of sequence. There are only 2 questions of recognition or recall of comparison. Furthermore, there are 15 reading comprehension questions which are categorized as recognition or recall of cause and effect relationships, and the rest, 16 questions recognize character traits. Further explanation is described as follows.

(1) Recognition or Recall of Details 
Most questions (155) of literal comprehension level are categorized into recognition or recall of details. Some of them are as follows.

- Where did the event take place? (A/1/1)

- Who is Sung-Min? (F/1/5)

- How many birds are in zoos? (D/2/3)

- How many birds are there at last counts? F/2/9

- Where can we find MacQuarie university? (D/3/5)

The questions ask the readers to identify information or idea explicitly stated in the text. The first question in the example above asks the student to identify or locate the place where the event in the text 1 takes place. As found in text 1, the answer is explicitly stated in the first paragraph. The questions fulfill the indicators in which they require the readers to recognize or recall the place (where), time (when), person (who) and quantity (how much/how many).

(2) Recognition or Recall of Main Idea

The questions ask facts which are explicitly stated in the text. There are 70 questions of literal comprehension level categorized as recognition or recall of main idea. Following are the samples of questions taken from the data.

- What is the main idea of the last paragraph? (D/1/9)

- What is the text mainly discussed? (K/2/1)

- What is the main purpose of the text? (D/3/3)

(3) Recognition or Recall of a Sequence

There are 13 questions of literal comprehension level categorized into recognition or recall of a sequence. The samples of the questions are as follows.

- What have the writer done before becoming a volunteer for rehabilitation residence? ( $/ / 1 / 2)$

- How did sung Min's finger before he had five discrete digits on each hand? (J/1/8)

- What did she/he do at second day? (H/1/8)

(4) Recognition or Recall of Comparison

Twenty one questions of literal comprehension levels were categorized into recognition or recall of comparison. Questions in this category ask the readers to identify likenesses and differences in characters, time, 
words and places that are explicitly stated in the text. The questions are as follows.

- What is the similar meaning of "reluctant" (line 1)? (J/1/7)

- What is the synonym of the word "steep" in the fourth paragraph line 3 ? (B/2/7)

- What is the synonym of the word "largest" in the text? $(M / 2 / 1)$

(5) Recognition or Recall of Cause and Effect Relationships

There are 15 questions of literal comprehension level categorized into recognition or recall of cause and effect relationships. Some of them are written below.

- Why did the writer's father ask her/him to work in a such rehabilitation residence? (A/1/8)

- Write the sentence in the text that tells why the authors say that Sung Min is the brightest one in the residence! (O/1/4)

- Why can't Jalak Putih be seen in its natural environment? $(J / 2 / 3)$

- According to the $5^{\text {th }}$ paragraph, why is Macquarie different from other universities in Australia? (M/3/7)

(6) Recognition or recall of Character Traits

The questions asking character traits require the readers to recognize in the selection or just recall from memory explicit statement about characters which illustrate the type of persons they are. There are 16 questions of recognition of character traits found in the data. Following are some of the questions.

- Did Sung Min have normal physical condition? Explain his condition! (C/1/9)

- Can you tell me, what did she/he feel as she/he saw Youngill? $(H / 1 / 5)$

- What was the writer's feeling as he joined the rehabilitation

2. Reorganization residence for mentally and physically? (J/1/9)

The results show that there are 52 questions of reorganization level. This level consists of four categories namely classifying, outlining, summarizing, and synthesizing. Reorganization questions in each category were discussed as follows.

(1). Classifying

Eighteen questions of reorganization level are classifying. They are: 
- What tenses is mostly used in the text? ( D/1/7)

- $\quad$ Name the characters described in the text? (I/1/2)

- What things make the university the most attractive campus? $(H / 3 / 5)$

\section{(2). Outlining}

No questions in the data belong to this category.

(3). Summarizing

The questions asking for summarizing require the readers to condense the text using direct or paraphrased statements from the text. There are 22 questions dealing with summarizing. They are as follows.

- $\quad$ What is the text about? (E/1/1, B/1/9, C/2/1, B/3/1, E/3/1, H/3/1, $L / 3 / 1, N / 3 / 1, O / 3 / 1)$

- $\quad$ What is the topic of the text? $(L / 1 / 1, N / 1 / 1, O / 1 / 1, B / 2 / 1, H / 2 / 2$, $N / 2 / 1, I / 3 / 1, K / 3 / 1)$

- $\quad$ What is the conclusion of the text above? (E/2/10)

- How can you describe West Bali National Park in 8 words? $(F / 2 / 6)$

- $\quad$ Describe the Mars Creek Zone clearly! (M/3/6)

\section{(4). Synthesizing}

There are 12 questions of reorganization level categorized as synthesizing. The questions are as follows.

- What kind of people did the writer meet that could make him/her ashamed? (A/1/6)

- What did he/she do during her/his day in the residence? $(O / 1 / 2)$

- In what year the university will be the only university with a railway station? $(H / 3 / 9, M / 3 / 2)$

The questions ask the readers to consolidate explicit ideas or information from more than one part of the text. The first question, for example, ask about people who could make the writer ashamed. As stated in the text explicitly, the answer of this question can be found in the first and 
the third paragraph of text 1 . so, in order to answer this questions, the readers should consolidate the first and the third paragraph about people who make the writer felt a much embarrassment. There are two teachers who wrote the questions as the third example above. In order to answer this question, the students have to put together two pieces of information that are from different parts of the text. It is stated in the first paragraph of text 3 that "this year, in 2004, it celebrates its $40^{\text {th }}$ anniversary" and then later in the last paragraph it also stated "in three years time, Macquarie will be the only university in Australia with a railway station". By synthesizing the two information from different part of the text the student would find out the answer of the third questions asked by teachers.

\section{Inferential}

The table 10 shows that there are 93 questions of inferential comprehension level. It was divided into 8 categories. 51 questions are inferring the main idea, 19 questions are classified as inference of figurative language, and 9 questions are inference of cause and effect relationships. Inference of predicting outcomes is 5 questions while 4 questions classified as inference of character traits and inferring comparison. The lowest proportion, only one question, is inferring of sequence. Further explanation of each category was discussed as follows.

(1). Inferring supporting details.

No questions in the data belong to this category.

\section{(2). Inferring Main Ideas}

The questions of inferring main ideas ask the readers to provide the main idea, general theme, or moral which is not explicitly stated in the text. There are 43 questions dealing with inferring main ideas. They are:

- What can we learn from the story? (B/1/5)

- $\quad$ What is the main idea of the last paragraph? (D/1/9)

- Write another title that you think appropriate to the text! $(I / 1 / 4)$

(3). Inferring Sequences 
There is only one question categorized as inferring sequences. The only question is as follows.

- What did the author do after he/she did the most difficult task at the resident? $(L / 1 / 7)$

Questions asking inferring sequences require the students to conjecture as to what action or incident might have taken place, hypothesize about what would happen next if the selection had not ended as it did but had been extended. As it can be seen on the only example above, the students are required to make intelligent hypothesis about what the author did after doing the most difficult task in the resident on the basis of explicit information from the text. The answer of this question is not explicitly stated in the text 1. Firstly, the students have to know what the most difficult task that the author did. answer.

(4). Inferring Comparison

There are 4 questions of inference comprehension level are inferring comparison. The questions are as follows.

- $\quad$ Compare the residents' behavior with the writer's! (G/1/9)

- $\quad$ Is there any differences between Macquarie in 1964 with that of today? Mention it! (C/3/4)

(5). Inferring Cause and Effect Relationships.

The questions of inferring cause and effect relationships ask the students to hypothesize about the motivations of characters and their interactions with time and place. They may also be required as to what caused the author to include certain ideas, words, characterizations, and actions in his writing. There are 9 questions dealing with inferring cause and effect relationships. They are as follows.

- What made the writer slowly agree with his/her father's request? $(A / 1 / 3)$

- Why does the international support the Bali Starling project? $(A / 2 / 3)$ 
- In your opinion, why a certain part of the park is not open for public? (N/2/8)

- Why MacQuarie university is called as the most interesting campus? (L/3/5)

\section{(6). Inferring Character Traits.}

Questions of inferring character traits ask the students to hypothesize the nature of characters on the basis of explicit clues stated in the text. Table 10 shows that 4 questions of inferential comprehension level are inferring character traits. The questions are:

- Can you guess what kind of people the writer is? (E/1/3)

- What kind of person do you think the writer is?(L/1/7)

- What kind of person do you think the author is? (N/1/7)

- What kind of person the author's father is? (O/1/8)

\section{Predicting Outcomes}

There are 5 questions of predicting outcomes. Questions of this category require the students to predict the outcomes on the basis of some information which is explicitly stated in the text and their prior knowledge. The questions are as follows.

- What was the writer going to do after he/she had got the meaningful experience? $(A / 1 / 10)$

- Do you think the writer will come to the residence again? Why? $(B / 1 / 8)$

- In your opinion, what will he/she do after visiting the residence? $(I / 1 / 5)$

\section{(1). Inferring Figurative Language}

Questions of inferring figurative language ask the students to infer literal meaning from the author's figurative language used in the text. There are 19 questions of this category. They are:

- What is the meaning of the word "conspicuous" in paragraph 1 ? $(G / 1 / 4)$ 
- The writer puts "however" in the fourth paragraph to describe ..... $(E / 2 / 5)$

- What does the writer mean by writing "....room to breathe" (the third paragraph)? (J/3/4)

\section{Evaluation}

Based on the table 10, there are 13 questions of evaluation level. Among five categories of evaluation, only two categories are covered by the questions. 7 questions are judgment of fact or opinion and the rest, one question, is judgment of adequacy and validity. The questions of each category are discussed in detail in the following explanation.

\section{(1). Judgments of Reality and Fantasy}

No questions in the data belong to this category.

(2). Judgments of Fact or Opinion

There are 6 reading comprehension questions asking for judgments of fact or opinion. The questions are as follows.

- In your opinion, is it possible for Indonesian students to do the program as the author described in the text? Clarify your answer! (O/1/9)

- What should the regional government do to overcome the problems? (A/2/10)

- What other activities that you can do to save the environment? (H/2/9)

\section{(3). Judgments of Adequacy and Validity}

Only one question of Evaluation level are categorized as judgments of adequacy and validity. The only question is as follows.

- Do you think that it is an expository text? Clarify your answer! (H/2/4)

Question asking for judgments of adequacy and validiy requires the students to analyze, evaluate and compare written sources of information, with an eye toward agreement and disagreement or completeness and incompleteness. As can be seen on the only example, the students are required to analyze the text on the basis of their knowledge on the 
characteristics of expository text before they decide whether the text is expository text or not.

(4). Judgments of appropriateness

No questions in the data belong to this category.

(5). Judgment of Worth, Desirability and Acceptability

No Questions in the data belong to this category.

\section{Appreciation}

Among 450 questions in the data, only two questions are categorized as appreciation comprehension level. Appreciation involves all the previously cited cognitive dimensions of reading, for it deals with the psychological and aesthetic impact of the text on the readers. It includes the knowledge of, and the emotional response to, literary techniques, forms, styles, and structure. Questions at evaluation levels were divided into four categories. They are emotional response to the content, identification with characters and incidents, reaction to the author's use of language, and imagery. Among the four categories, only two categories were covered by the questions. They are discussed as follows.

\section{(1). Emotional Response to The Content}

Questions in this category require the students to verbalize their feelings about the text in terms of interest, excitement, boredom, fear, hate, amusement, etc. it is concerned with the emotional impact of the total work on the students. The question "How do you feel about the residents?" (B/1/7) ask the students to verbalize their feelings about the residents described in the text.

\section{(2). Identification with Characters or Incidents.}

Teachers' questions in this type will elicit responses from the students which demonstrate his sensitivity to, sympathy for, and empathy with the characters and happenings in the text. The question found in the data is:

"It is stated that 3000 birds are in zoos and private collections. Do you agree if the birds are reserved in the zoo? Why?". (H/2/6)

To response to this question, the student should think about the condition of the birds in zoos and use their sensitivity to the condition of the birds in their responses. 


\section{(3). Reactions to the Author's Use of Language}

No questions in the data belong to this category.

(4). Imagery

No questions in the data belong to this category.

\section{The Unsatisfactory Questions}

The term unsatisfactory questions are referred to the questions that can be answered without reading text where the questions are based. Nuttal (1982) suggests a guideline to assess reading comprehension questions developed by teachers and reading test developers. One of the guidelines is to recognize whether the reading comprehension questions can be answered without the presence of the reading text.

Findings show that there are 18 questions that are categorized as unsatisfactory questions because the questions give big chance for students to answer correctly without reading the passage. The questions are as follows.

- In your opinion, what is the meaning of the word "community service"? (F/1/6)

- What are the synonyms of these words? (F/1/7)
a. Anxiety
b. reluctant

- $\quad$ In what island is the west Bali National Park located? (A/2/1)

\section{Discussion}

To make the discussion meaningful, a summary of the research findings is desirable. In short, the findings of the study can be explained as follows.

1. The types of comprehension question developed by English teachers of SMA are yes/no questions, Wh-questions, and "other" questions.

2. The most dominant type is Wh-questions (87,3\%), followed by yes/no questions $(6,7 \%)$, and the lowest portion of the type is "other" questions $(6 \%)$.

3. The levels of comprehension covered in reading comprehension questions developed by teachers are literal, reorganization, inferential, evaluation, and appreciation. The dominant level is literal comprehension. 
Furthermore, Day and Park (2005) states that questions beginning with where, what, when, who, how, and why are excellent in helping students with a literal understanding of the text, with reorganizing information in the text, and making evaluations, personal responses and predictions. In particular, how and why can help students to go beyond a literal understanding of the text and become interactive readers. This research finding found that most of wh-questions are formed in "what" type and almost all questions in literal comprehension level are formed in this type. It means that teachers need to provide more how and why types as they instructed students in understanding text and promoted critical thinking.

Other findings show that the variety of comprehension questions developed by teachers are still dominated with literal or the lowest level of comprehension based on Barrett's taxonomy. Certainly, no one suggests that all questions should in high level. Indeed, the use of factual questions can be defended on the grounds that students need to know certain basic information before they can engage in higher order thinking.

Nuttal (1989: 134) suggested that the types of comprehension questions could be asked from the most elementary level. But inference, evaluation and appreciation should be the most concern since the questions of these types force the readers to think about not just what the writer has written, but how he has written it. Unless the students think about that, they are not likely to become as competent as the teachers would like in tackling difficult texts. In conclusion, questions with literal comprehension still important to develop higher thinking questions.

In Addition, there are some categories that have not been covered by the questions developed by English language teachers. They are judgment of reality and fantasy, judgment of appropriateness, judgment of worth, desirability and acceptability in the evaluation, and reactional to the author's use of language and imagery in the appreciation level. There are three possible causes that may account for the fact that there is no question developed by teachers belong to these categories. The first is dealing with the choice of the texts. Since one of the goals in teaching reading is to equip the students to be active readers, the texts chosen should enable the teacher to ask various types and levels of comprehension questions. It is 
difficult for the teachers to ask evaluative or appreciative questions if the text does not enable them to do so.

The second reason is dealing with the teacher's creativity in developing reading comprehension questions. To develop various questions is not an easy task to do. Teachers are required to have a good comprehension of the text and knowledge about good reading comprehension questions. Simple text can be exploited to make some questions in higher level of comprehension however for beginning and intermediate students (Nuttal, 1982:133)

The third reason is dealing with cultural aspects. It is common that some teachers may be reluctant to ask critical questions as evaluative and appreciative questions. They seem to hesitate to take risks by asking questions asking students to judge or force arguments about the text since they did not use to accept disagreement and critics.

\section{Conclusion}

Well-developed comprehension questions are important because they help the learners interact with the text to create meaning and begin to think critically and intelligently. Thus, it is important for the English teachers to have good ability in developing reading comprehension questions by using various type and level of comprehension. The main aim of this study is to investigate the types and levels of reading comprehension questions developed by English teacher of Senior High Schools in Surabaya. The study was inspired by the fact that teachers tend to ask questions in lower level of comprehension than the higher one.

Based on the objective of the study as stated above, a descriptive study was then employed in this study. The questions were analyzed based on the question types and levels of comprehension. Then, the study also is to identify the bias questions or what Nuttal (1982) called as "unsatisfactory" question, in which the questions in this category give big opportunity to be answered correctly without the presence of the reading text.

Teachers tend to use more wh-questions $(87,7 \%)$ than yes-no $(7 \%)$ and 'other' $(5,3 \%)$ question types throughout his students. The type of wh- questions that 
commonly used is "what" questions . It means that the teachers are still interested in asking questions in lower level of questions rather than in "why" and "how" which is referred to a higher level of thinking.

The variety of comprehension questions developed by teachers is still dominated with literal $(373 \%)$ or the lowest level of comprehension based on Barrett's taxonomy. Certainly, no one suggests that all questions should in high level. Indeed, the use of factual questions can be defended on the grounds that students need to know certain basic information before they can engage in higher order thinking. To stimulate the students' understanding of a text, the questions should involve various types of comprehension questions. In other words, each type of questions plays a valuable role in helping teachers understand the important ways in which students have to develop. Hence, the literal and higher levels of comprehension are important in reading, the number of question in both ideally is balance.

\section{References}

Barrett, T.C. 1972. Taxonomy of Reading Comprehension: Reading 360 Monograph. Lexington, MA: Ginn and Co.

Brown, H. Douglas. 2003. Language Assessment: Principles and Classroom Practices. White Plains, NY: Pearson Education.

Cook, G. 1997. Key Concepts in ELT: Schemas. ELT Journal, 51 (1): 28-40.

Day, Richard R. and Jeong sun Park. October 21, 2005. Developing Reading Comprehension Questions. Reading in a Foreign Language, (online), Vol.3, No.7. (http://www.nflrc.Hawaii.edu/rfl, accessed on December 12, 2007)

Gunning, T.G. 2000. Creating Literacy Instruction for All Children. Needham Heights,MA: Allyn and Bacon.

Grabe, W. and L. Stoller, F. 2002. Teaching and Researching Reading. Harlow: Pearson Education.

Hill, C. A., and Larsen, E. 2000. Children and Reading Tests. Connecticut: Ablex.

Hornby, A.S. 1998. Oxford Advanced Learner: A Dictionary of Current English. Randolp Quirk. Oxford: Oxford University Press. 
Mason, Jana M. 1990. Reading Instruction for Today. United States of America: Harper Collins

Morgan, N. and J. Saxon. 1994. Asking Better Questions. Markham, ON: Pembroke.

Nuttal, C. 1998. Teaching Reading Skills in a Foreign Language. Oxford: Heinemann.

Pearson, P.D. and Johnson, D.D. 1978. Teaching Reading Comprehension. New York: Holt, Rinehart and Winston.

Pressley, M., Wharton McDonald, R., Allington, R., Block, C. C., Morrow, L., Tracy, D., Baker, K., Brooks, G., Cronin, J., Nelson, E., and Woo, D. 2001. A Study of Effective First-Grade Literacy Instruction. Scientific Study of Reading, 1 (5): 35-58.

Richards, Jack C. 2001. Curriculum Development in Language Teaching. Cambridge: Cambridge Language Education.

Scales, Alice M. and Li-Bi Shen. September 21, 2001. An Investigation of Questions in McGuffey's Second Eclectic Readers. Reading Online, (online), (http://www.readingonline.org/articles/scales, accessed on December 12, 2007).

Smith, R.J., and Barrett, T.C. 1974. Teaching Reading in the Middle Grades. Reading, MA: Addison-Wesley.

Sunggingwati, Dyah. 2001. Reading Questions of Junior High School English Textbooks. Unpublished Master's Thesis. Malang: Graduate Program of the Malang University.

Swaby, B.E.R. 1984. Teaching and Learning Reading: A Pragmatic Approach. Boston, MA: Little Brown.

Tingastuti S, Tjahjaning. 1991. The Effect of Different Types of Questions on Reading Ability of Students. Master's Thesis. Malang: Graduate Program of the Malang University.. 